\title{
Patient relevant outcomes of unicompartmental versus total knee replacement: systematic review and meta-analysis
}

\author{
Hannah A Wilson, ${ }^{1}$ Rob Middleton, ${ }^{1}$ Simon G F Abram, ${ }^{1}$ Stephanie Smith, ${ }^{1}$ Abtin Alvand, ${ }^{1}$ \\ William F Jackson, ${ }^{2}$ Nicholas Bottomley, ${ }^{2}$ Sally Hopewell, ${ }^{3}$ Andrew J Price ${ }^{1}$
}

${ }^{1}$ University of Oxford,

Nuffield Department of

Orthopaedics Rheumatology

and Musculoskeletal Sciences,

BOTNAR Research Centre,

Headington, Oxford OX3 7LD,

UK

${ }^{2}$ Oxford University Hospitals

NHS Trust, Nuffield Orthopaedic

Centre, Oxford, UK

${ }^{3}$ Centre for Statistics in

Medicine, Oxford Clinical Trials

Research Unit, Oxford, UK

Correspondence to: $\mathrm{H}$ A Wilson hannah.wilson@ndorms.ox.ac.uk (ORCID 0000-0002-9351-1592) Additional material is published online only. To view please visit the journal online.

Cite this as: $B M J$ 2019;364:1352 http://dx.doi.org/10.1136/bmj.1352

Accepted: 14 January 2019

\section{ABSTRACT}

OBJECTIVE

To present a clear and comprehensive summary of the published data on unicompartmental knee replacement (UKA) or total knee replacement (TKA), comparing domains of outcome that have been shown to be important to patients and clinicians to allow informed decision making.

DESIGN

Systematic review using data from randomised controlled trials, nationwide databases or joint registries, and large cohort studies.

\section{DATA SOURCES}

Medline, Embase, Cochrane Controlled Register of Trials (CENTRAL), and Clinical Trials.gov, searched between 1 January 1997 and 31 December 2018.

ELIGIBILITY CRITERIA FOR SELECTING STUDIES

Studies published in the past 20 years, comparing outcomes of primary UKA with TKA in adult patients. Studies were excluded if they involved fewer than 50 participants, or if translation into English was not available.

\section{RESULTS \\ 60 eligible studies were separated into three methodological groups: seven publications from six randomised controlled trials, 17 national joint registries and national database studies, and 36 cohort studies. Results for each domain of outcome varied depending on the level of data, and findings were not always significant. Analysis of the three groups of studies showed significantly shorter hospital stays after UKA than after TKA $(-1.20$ days (95\% confidence interval -1.67 to -0.73 ), -1.43 $(-1.53$ to -1.33$)$, and $-1.73(-2.30$ to -1.16$)$,}

\section{WHAT IS ALREADY KNOWN ON THIS TOPIC}

Partial (or unicompartmental) and total knee replacement are both viable surgical options for treating unicompartmental knee osteoarthritis, but most patients with this condition currently undergo total knee replacement

Many patients are not offered partial knee replacement as part of the shared decision making process

The revision rate for total knee replacement is lower than for partial knee replacement in the longer term, but complication rates are lower after partial procedures in the shorter term

\section{WHAT THIS STUDY ADDS}

Partial knee replacement has several advantages over total knee replacement, including shorter time in hospital, fewer serious medical complications, lower mortality, lower deep infection rate, and better functional outcome

Revision surgery is less likely after total knee replacement, but reoperation for other causes occurs at the same rate for both procedures

This evidence should be used to inform shared decision making for patients respectively). There was no significant difference in pain, based on patient reported outcome measures (PROMs), but significantly better functional PROM scores for UKA than for TKA in both non-trial groups (standard mean difference $-0.58(-0.88$ to -0.27$)$ and -0.29 ( -0.46 to -0.11$)$, respectively). Regarding major complications, trials and cohort studies had non-significant results, but mortality after TKA was significantly higher in registry and large database studies (risk ratio 0.27 (0.16 to 0.45$)$ ), as were venous thromboembolic events (0.39 (0.27 to 0.57)) and major cardiac events (0.22 (0.06 to 0.86)). Early reoperation for any reason was higher after TKA than after UKA, but revision rates at five years remained higher for UKA in all three study groups (risk ratio 5.95 (1.29 to 27.59 ), 2.50 (1.77 to 3.54), and 3.13 (1.89 to 5.17), respectively).

\section{CONCLUSIONS}

TKA and UKA are both viable options for the treatment of isolated unicompartmental osteoarthritis. By directly comparing the two treatments, this study demonstrates better results for UKA in several outcome domains. However, the risk of revision surgery was lower for TKA. This information should be available to patients as part of the shared decision making process in choosing treatment options.

\section{SYSTEMATIC REVIEW REGISTRATION}

PROSPERO number CRD42018089972.

\section{Introduction}

Partial or unicompartmental knee arthroplasty (UKA) and total knee arthroplasty (TKA) are well established treatment options for end stage medial compartment osteoarthritis, in patients in whom conservative management options have failed. ${ }^{1}$ An estimated 25 $47 \%$ of patients who are eligible for primary joint replacement in the United Kingdom have isolated unicompartmental osteoarthritis, and would be eligible to receive either implant. ${ }^{2-4}$ However, the rate of implantation of UKA in the UK remains static at around $8 \%$ of all primary knee joint arthroplasties, and varies enormously both geographically and between centres in the same region. ${ }^{5}$ This is likely to reflect the fact that only $38 \%(n=651)$ of the 1715 clinicians who reported performing total knee arthroplasty to the UK National Joint Registry in 2017 also performed UKA. ${ }^{5}$

The debate regarding UKA or TKA as the treatment of choice for eligible patients continues. ${ }^{1}$ The higher revision rates for UKA than for TKA, as reported in national joint registries and a recent meta-analysis, ${ }^{6}$ particularly in younger patients, is thought to be a key factor in explaining why more knee surgeons do not perform both procedures. ${ }^{7}$ But recent literature 
has shown that the higher failure rates of UKA are associated with centres and surgeons performing low numbers of the procedure. ${ }^{8-12}$ Some evidence in the UK also suggests that UKA has significant advantages over TKA, with fewer serious medical complications, reduced mortality rates, faster recovery, and superior functional outcome. ${ }^{13-15}$

In reality, when considering between two recognised treatment options for the same condition, the decision should be shared between the patient and the clinician. ${ }^{16}$ Many medical decisions can only be made once both parties are able to understand and compare the risks and benefits of both treatment options. ${ }^{16-18}$ A wide range of outcomes, relative risks, and potential benefits of each treatment option must be understood and applied to each individual patient. If the full spectrum of outcomes is not considered, then patients cannot be considered as fully informed. ${ }^{19} 20$ When deciding whether to undergo knee arthroplasty surgery, several key outcome domains are important to patients, such as speed of recovery, return to work, revision, complications, mortality, and functional outcomes. $^{13}$ 21-24 Data regarding these outcome domains have been reported in the literature, but very few randomised controlled trials and few of the published studies' methodologies have compared TKA with UKA for multiple outcomes. A recently completed James Lind Alliance priority setting partnership identified the issue of describing outcomes and offering information to patients as a priority for future research. $^{25}$

Systematic review methodology, with meta-analysis, allows comparison of UKA and TKA across several outcome fields. Previous systematic reviews have used small numbers of studies, using only data from randomised controlled trials ${ }^{26}$ or using data from studies investigating UKA or TKA individually, often focusing on clinician orientated outcome measures. ${ }^{2728}$ In the present study, we expanded inclusion criteria beyond trials to include other study methodologies, such as registry and multicentre database analyses and large cohort studies. As a result, it was possible to study more outcome domains, and include outcome data from far more procedures.

These studies presented data collected with such different methodologies that they could not be included in one analysis. Therefore, in the current study, we created three groups of studies: group 1 including data from randomised controlled trials, group 2 including data from national joint registries and large nationwide multicentre databases, and group 3 including data from large cohort studies. Therefore, for each domain of outcome, three separate analyses were presented simultaneously where possible. Therefore, if there was a statistically significant agreement across all the study groups, we thought that this would present a compelling result when comparing the two implant types. If there was disagreement between the groups of studies, the relevant limitations of each groups' data and or study methodologies could then be considered.
The aim of the present study was to provide a synthesis of evidence from randomised controlled trials, registries and nationally reported databases, and cohort studies, in all outcome domains identified as important by patients undergoing UKA or TKA. This evidence was to enable informed shared decision making in the care of patients when choosing an implant to treat unicompartmental osteoarthritis of the knee.

\section{Methods}

This study was conducted in accordance with the MOOSE (meta-analysis of observational studies in epidemiology) $^{29}$ and PRISMA (preferred reporting items for systematic reviews and meta-analyses) guidelines. $^{30}$

\section{Literature search and selection of studies}

We conducted a systematic search of Medline, Embase, Cochrane Controlled Register of Trials (CENTRAL), and Clinical Trials.gov, to identify relevant studies published in English between 1 January 1997 and 31 December 2018. The search was limited to studies published in the past 20 years, in order to focus on studies involving modern implants. We excluded conference abstracts and case reports unless they had subsequently been published as full articles. The search strategy is described in appendix 1.

Studies were initially selected on the basis of their title and abstract by two independent authors (HAW and RM). In the case of any disagreement or uncertainty, full papers were retrieved and reviewed, and discussed with a third author (AP). We included randomised controlled trials, retrospective analyses of large national or multicentre databases or joint registries, and large cohort studies. The search was limited to studies that directly compared outcomes of UKA and TKA, in adult patients (age $\geq 18$ years). Studies focusing on the isolated patellofemoral joint or isolated lateral compartment osteoarthritis were also excluded. To avoid overestimating any outcome, we required each study to include a minimum of 50 participants. Studies were also required to have a minimum follow-up of 30 days if assessing an adverse event, or a minimum of six months if assessing outcome data. Studies were excluded if the data presented were insufficient to pool for statistical analysis. Where possible, non-English studies were translated and included into the study. Supplementary table 1 lists a summary of all studies included and their key features.

\section{Selection of domains of outcomes to be investigated}

The outcome measures were identified after discussion groups in our unit, with patients who had previously undergone knee arthroplasty surgery. We also took into account the most commonly used measures of outcome from recent publications. Domains included:

- Hospital admission impact: length of operation and length of hospital stay 
- Risk of early complications (myocardial infarction, stroke, venous thromboembolism, or deep infection) or early mortality

- Success of operation: range of movement achieved or kneeling ability, reduction in pain, improvement in function

- Reoperation or revision rate

- Rate of recovery: rate of return to work, rate of return to sporting activities.

We found agreement on the most important outcome domains between the literature search and the patient discussion group. The patient's discussion group valued information such as return to work and sporting activities more highly, and also suggested inclusion of information regarding length and acceptability or appearance of the operative scar. Furthermore, the literature search demonstrated multiple studies comparing differences in implant design, surgical approach, blood loss or transfusion rates, and cost effectiveness of UKA versus TKA. ${ }^{31-34}$ These aspects of surgical technique and implant implications were not included in the analysis of this study because we believed that they would not ordinarily be considered when informing patient decision making.

\section{Data extraction}

Data were extracted by use of standardised forms. Two authors (HW, RM) independently extracted the data from all included studies. Where available, data recorded included general study characteristics such as the name of the lead investigator and year of publication, recruitment period, median duration of follow-up, number of participants, and mean age and sex of the participants. Furthermore, the primary outcome measures and adverse event data were extracted (appendix 1b, supplementary figures).

Studies were initially categorised into three groups: randomised controlled trials (group 1), national or large multicentre database or joint registry studies (group 2), and large cohort studies (group 3). There were insufficient numbers of studies providing data that were adequately adjusted to be analysed separately, mainly because studies often did not adjusted for grade or stage of osteoarthritis, as well as for age, sex, and health status. If data presented were incomplete, efforts were made to contact the corresponding author for further information.

\section{Risk of bias}

We assessed risk of bias using the Cochrane collaboration's tool for assessing risk of bias for randomised controlled trials, ${ }^{35}$ stratifying the risk as high, unclear, or low risk in a traffic light configuration for random sequence generation, allocation concealment, blinding of participants, blinding of outcome, and attrition bias. Assessments are reported in supplementary table 2 . For the study groups 2 and 3 , we used the Newcastle-Ottawa scale ${ }^{36}$ to assess studies in four key areas, including selection and comparability of cohorts, and outcome assessment and follow-up. Each domain of risk was again classified into low, unclear, or high risk, and presented in a summary table (supplementary table 3).

\section{Statistical analysis}

We calculated the overall summary estimates using inverse variance weighted random effects metaanalysis. Individual relative risk estimates and summary estimates were displayed graphically in forest plats. Heterogeneity was quantified with the $\mathrm{I}^{2}$ statistic and $Q$ test. Analysis could not be carried across the different types of study owing to the significant difference in their design. Therefore, for each outcome, data from each type of study were presented sequentially as randomised controlled trials, registry studies, and then large cohort studies. If no data were presented in one or more of the groups of publications for an outcome, we commented on this.

\section{Patient and public involvement}

Patient discussion groups were used as a means of involving patients in setting the research question and for determining the outcome measures. Patients were not asked to advise on the study interpretation or participate in the writing up of results. Patients will not be involved in the dissemination of results.

\section{Results}

Of 1289 studies eligible for inclusion in the abstract screen, 1201 were excluded for not meeting the inclusion criteria and repetition. After full text review, a further 28 studies were excluded,,$^{32} 34$ and 60 were included in the final analysis (fig 1).

Group 1 included seven publications. Of five primary randomised controlled trial papers, ${ }^{63-66}$ two included patients who underwent a TKA in one knee and a UKA in the contralateral leg, ${ }^{6465}$ and one included patients who received either simultaneous bilateral UKA or TKAs. ${ }^{67}$ The remaining two publications were subsequent reports. ${ }^{6869}$ This allowed a maximum analysis of 898 implants in 764 patients from the trial data.

Group 2 included 12 publications from seven national joint registries ${ }^{813142370-79}$ and five multicentre database studies. ${ }^{80-84}$ The non-national joint registry studies were included in this group because their data collection methods and patient cohorts were more akin to registry studies than cohort studies. Examples include studies in which data were requested to answer specific research questions from an established database, data were collected from multiple hospitals and from different clinicians, and different implants were used with no control on operative technique or postoperative care. Some data on the same procedures were presented in different studies as part of different cohorts, so we were unable to calculate the actual number of procedures.

A further 36 cohort studies were included in group 3. Of these studies including data comparisons between UKAs and TKAs, ${ }^{15} 3182$ 85-114 only five included data specifically in patients with anteromedial osteoarthritis. $^{15} 8599103111$ Again, we saw some crossover in the data presented from the same unit 


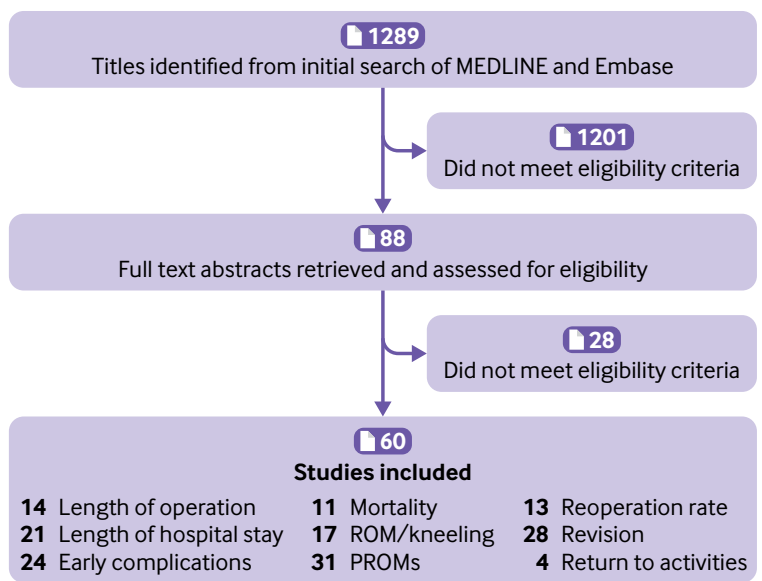

Fig 1 | Flowchart of studies reviewed and included for each analysis. Data were included from 60 studies, several of which contributed to analyses for several domains of outcome. ROMS=range of motion; PROMs=patient reported outcome measures

in multiple papers, but the maximum number of implants was 26418. Of the 60 studies included in the final analysis, 14 reported on length of operation, 21 on length of hospital stay, 24 on complication rates, 11 on early mortality rates, 17 on range of motion and kneeling ability, 31 on patient reported outcome measures (PROMs), 13 on reoperations, 28 on revision rates, and four on return to work (fig 1).

\section{Outcomes}

For each outcome measure, data from study groups 1-3 were presented sequentially, for ease of comparison. If no data or inadequate data were available at any level, it was represented by a zero in the results table. For ease of interpretation, all the outcome data were presented in forest plots with UKA favourable results presented on the left hand axis and TKA favourable results on the right hand axis. A summary of all data analyses are presented in table 1.

\section{Domain 1: hospital admission impact Operation duration}

Fourteen studies involving a maximum of 3262 UKA and 53989 TKA procedures reported results for length of operation. "Operation duration" was often not defined in the studies, but all times were recorded in minutes. In group 1, data from three randomised controlled trials ${ }^{65-67}$ showed no difference in operating times between UKA and TKA (mean difference -1.72 minutes, 95\% confidence interval -11.89 to 8.45 ). Data from group 2 included two studies, ${ }^{8183}$ with a corresponding mean difference of -3.21 minutes $(-6.33$ to -0.09$)$. Data from nine cohort

\begin{tabular}{|c|c|c|c|c|c|c|c|c|c|}
\hline \multirow[b]{2}{*}{ Outcome domain } & \multicolumn{3}{|l|}{ Study group 1} & \multicolumn{3}{|l|}{ Study group 2} & \multicolumn{3}{|l|}{ Study group 3} \\
\hline & $\begin{array}{l}\text { Mean difference } \\
(95 \% \mathrm{Cl})\end{array}$ & $\begin{array}{l}I^{2} \\
(\%)\end{array}$ & Q test & $\begin{array}{l}\text { Mean difference } \\
(95 \% \mathrm{Cl})\end{array}$ & $\begin{array}{l}I^{2} \\
(\%)\end{array}$ & $Q$ test & $\begin{array}{l}\text { Mean difference } \\
(95 \% \mathrm{Cl})\end{array}$ & $\begin{array}{l}\mathrm{I}^{2} \\
(\%)\end{array}$ & $Q$ test \\
\hline \multicolumn{10}{|c|}{ Domain 1: hospital admission impact } \\
\hline $\begin{array}{l}\text { Operation duration } \\
\text { (mins) }\end{array}$ & $-1.72(-11.89$ to 8.45$)$ & 90 & $0.33(P=0.74)$ & ${ }^{*}-3.21(-6.33$ to 0.09$)$ & 23 & $2.01(P=0.04)$ & ${ }^{\star}-23.80(-37.81$ to -9.79$)$ & 98 & $3.33(P \leq 0.001)$ \\
\hline $\begin{array}{l}\text { Length of hospital } \\
\text { stay (days) }\end{array}$ & *1.20 (-1.67 to -0.73$)$ & - & $4.96(P \leq 0.001)$ & ${ }^{*}-1.43(-1.53$ to -1.33$)$ & 85 & $28.08(P \leq 0.001)$ & * $-1.73(-2.30$ to -1.16$)$ & 99 & $5.96(P \leq 0.001)$ \\
\hline \multicolumn{10}{|c|}{ Domain 2: risk of early complications or mortality (risk ratio) } \\
\hline Risk of MI & ${ }^{*} 0.33(0.01$ to 8.14$)$ & - & $0.67(P=0.5)$ & ${ }^{\star} 0.22(0.06$ to 0.86$)$ & 52 & $2.18(P=0.03)$ & $1.45(0.46$ to 4.55$)$ & 0 & $0.63(P=0.53)$ \\
\hline Risk of CVA & - & - & - & ${ }^{\star} 0.34(0.15$ to 0.74$)$ & 0 & $2.69(P=0.007)$ & - & - & - \\
\hline Risk of VTE & $0.24(0.04$ to 1.37$)$ & 0 & $1.61(P=0.11)$ & ${ }^{\star} 0.39(0.27$ to 0.57$)$ & 44 & $4.82(P<0.001)$ & $0.49(0.20$ to 1.17$)$ & 0 & $1.61(P=0.11)$ \\
\hline Risk of deep infection & - & - & - & ${ }^{\star} 0.59$ (0.43 to 0.82$)$ & 52 & $3.13(P=0.002)$ & ${ }^{\star} 0.40(0.16$ to 1.01$)$ & 0 & $1.94(P=0.05)$ \\
\hline Early mortality risk & - & - & - & ${ }^{\star} 0.27(0.16$ to 0.45$)$ & 21 & $5.02(P<0.001)$ & - & - & - \\
\hline \multicolumn{10}{|c|}{ Domain 3: success of operation } \\
\hline $\begin{array}{l}\text { Range of movement } \\
\text { (degrees) }\end{array}$ & $-4.58(-10.75$ to 1.59$)$ & 95 & $1.45(P=0.15)$ & ${ }^{*}-5.00(-7.28$ to -2.72$)$ & - & $4.29(P<0.001)$ & ${ }^{\star}-8.71(-11.77$ to -5.64$)$ & 98 & $5.57(P<0.001)$ \\
\hline $\begin{array}{l}\text { Kneeling ability } \\
\text { (risk ratio) }\end{array}$ & - & - & - & - & - & - & ${ }^{\star} 0.53(0.28$ to 1.01$)$ & 86 & $1.93(P=0.05)$ \\
\hline \multicolumn{10}{|c|}{ Patient reported outcome measures (scores) } \\
\hline Combined & ${ }^{\star}-0.19(-0.32$ to -0.05$)$ & 0 & $2.73(P=0.006)$ & $-0.05(-0.25$ to 0.15$)$ & 95 & $0.49(P=0.63)$ & ${ }^{\star}-0.19(-0.31$ to -0.06$)$ & 75 & $2.93(P=0.003)$ \\
\hline Pain & $-0.30(-0.63$ to 0.03$)$ & 0 & $1.80(P=0.07)$ & $-0.23(-0.46$ to 0.00$)$ & 92 & $1.96(P=0.05)$ & $-0.08(-0.35$ to 0.20$)$ & 83 & $0.56(P=0.57)$ \\
\hline Function & $-0.12(-0.28$ to 0.04$)$ & 0 & $1.50(P=0.13)$ & ${ }^{\star}-0.58(-0.88$ to -0.27$)$ & 95 & $3.70(P=0.002)$ & ${ }^{*}-0.29(-0.46$ to -0.11$)$ & 73 & $3.2(P=0.001)$ \\
\hline \multicolumn{10}{|c|}{ Domain 4: reoperation or revision rate } \\
\hline $\begin{array}{l}\text { Reoperation } \\
\text { (risk ratio) }\end{array}$ & 0.73 (0.27 to 2.02) & 0 & $0.60(P=0.55)$ & $1.05(0.75$ to 1.46$)$ & 66 & $0.27(P=0.79)$ & ${ }^{\star} 0.45$ (0.31 to 0.65$)$ & 11 & $4.17(P<0.001)$ \\
\hline \multicolumn{10}{|l|}{ Revision (risk ratio) } \\
\hline At 5 years & *5.95 (1.29 to 27.52$)$ & 0 & $2.28(P=0.02)$ & ${ }^{\star} 2.50(1.77$ to 3.54$)$ & 94 & $5.18(P<0.001)$ & ${ }^{*} 3.13$ (1.89 to 5.17$)$ & 50 & $3.31(P<0.001)$ \\
\hline At 10 years & $0.64(0.19$ to 2.14$)$ & - & $0.72(P=0.47)$ & ${ }^{\star} 1.85$ (1.43 to 2.38$)$ & 95 & $4.74(\mathrm{P}<0.001)$ & *1.68 (1.07 to 2.64$)$ & 58 & $2.24(P=0.03)$ \\
\hline At 15 years & 0.64 (0.19 to 2.14$)$ & - & $0.72(P=0.47)$ & *5.18 (1.39 to 19.22$)$ & 100 & $2.46(P=0.01)$ & - & - & - \\
\hline \multicolumn{10}{|c|}{ Domain 5: rate of recovery } \\
\hline $\begin{array}{l}\text { Return to work } \\
\text { (weeks) }\end{array}$ & - & - & - & - & - & - & ${ }^{*}-0.96(-1.31$ to -0.61$)$ & 0 & $5.42(P<0.001)$ \\
\hline $\begin{array}{l}\text { Return to sport } \\
\text { (weeks) }\end{array}$ & - & - & - & - & - & - & ${ }^{\star}-5.24(-6.84$ to -3.64$)$ & 96 & $6.41(P<0.001)$ \\
\hline
\end{tabular}


risk ratio of 0.39 (0.27 to 0.57$)$. In group 3 , data from four cohort studies 101104107112 showed a risk ratio of 0.49 (0.20 to 1.17 ).

\section{Deep infection}

A total of 15 studies reported incidence of deep infection after UKA or TKA, including data from a maximum of 23274 UKA and 259299 TKA procedures (supplementary figure 6). Deep infection was classified as infection that requires further intervention-ether revision, reoperation (debridement and implant retention), or long term suppressive antibiotics. We did not include superficial wound infections because they were frequently reported inconsistently or not reported. In group 1, data were presented from only one randomised controlled trial ${ }^{66}$ but no deep infections were reported. In group 2, data from six studies $^{717579818284}$ showed a reduced rate of infection after UKA, with a risk ratio of 0.59 (95\% confidence interval 0.43 to 0.82). Data from eight cohort

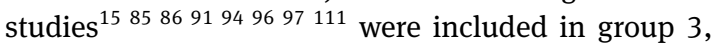
which showed a risk ratio of 0.40 (0.16 to 1.01$)$

\section{Early mortality}

We included all cause mortality reported within the first 45 days after the procedure; 10 studies were included, with a maximum of 73585 UKA and 696778 TKA procedures. TKA was associated with a significantly higher risk of early mortality than UKA in the one group of studies that supplied sufficient data (fig 4). In group 1, four randomised controlled trials ${ }^{63-66}$ reported no early mortalities, and so could not be included in the analysis. Data from six studies ${ }^{13} 1481-84$ were included in group 2, showing a risk ratio of 0.27 (95\% confidence interval 0.16 to 0.45 ). In group 3 , data for this domain were reported in one cohort study, ${ }^{104}$ but also did not show any early mortalities, and so could not be included in the analysis.

\section{Domain 3: success of operation Range of movement}

Seventeen studies reported postoperative range of movements in degrees for a maximum of 2541 UKA and 3848 TKAs; several studies reported only the improvement or difference in range of movement, which could not be included because the data were not comparable. The studies included showed a greater range of movement after UKA than TKA, but the results were only significant in groups 2 and 3 (supplementary figure 8). In group 1, data were presented from three randomised controlled trials, ${ }^{636568}$ which showed a mean difference of -4.58 degrees (95\% confidence interval -10.75 to 1.59). Data from one study ${ }^{95}$ could be included in group 2, which showed a mean difference of -5.00 degrees $(-7.28$ to -2.72$)$. Data from 13 cohort studies ${ }^{15} 5485-879091959699104106111$ in the

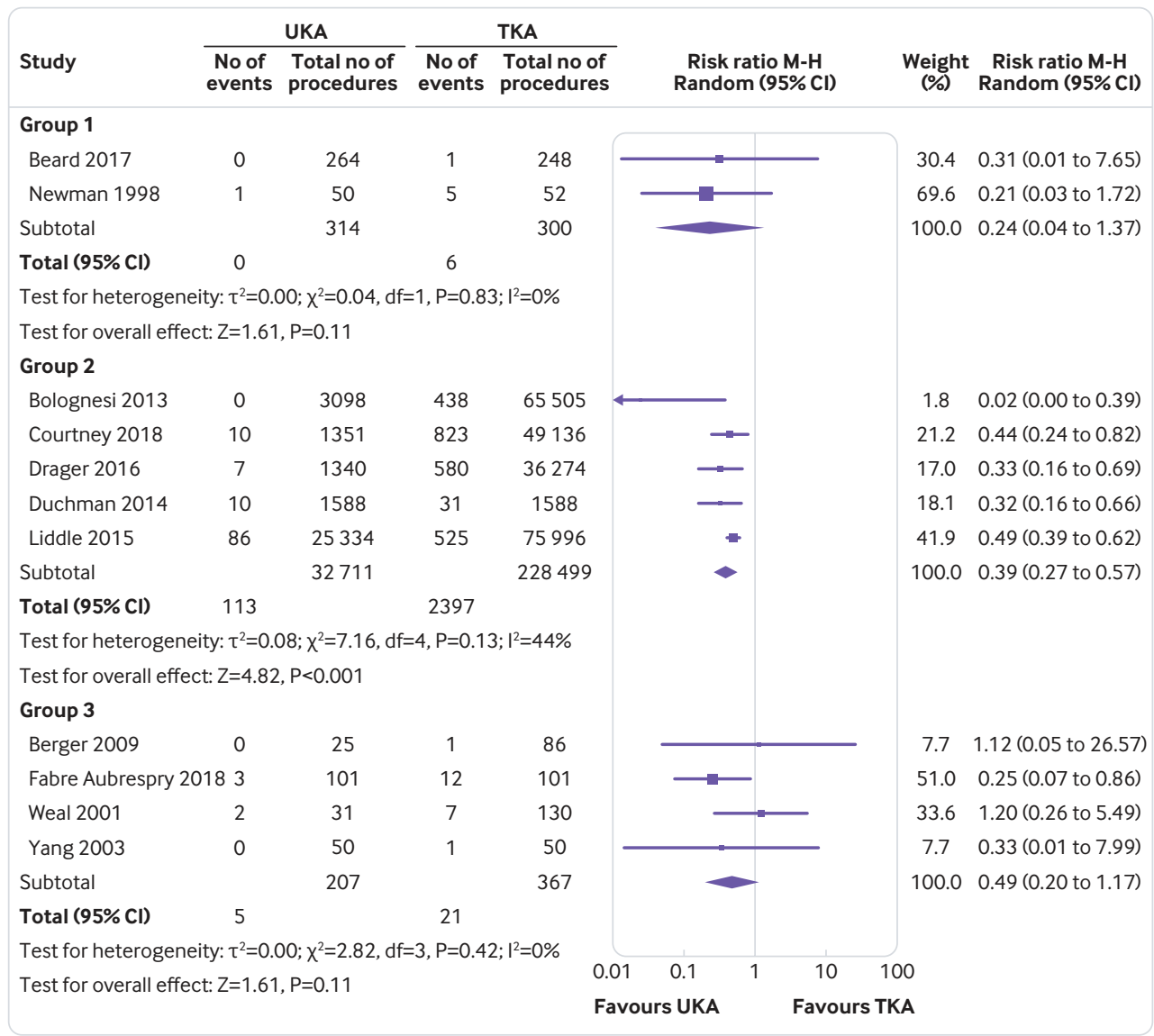

Fig 3 | Forest plot comparing risk of venous thromboembolism after unicompartmental (UKA) versus total knee replacement (TKA). Also appears in the supplementary material as supplementary figure $5 . \mathrm{M}-\mathrm{H}=\mathrm{Mantel}$-Haenszel test 


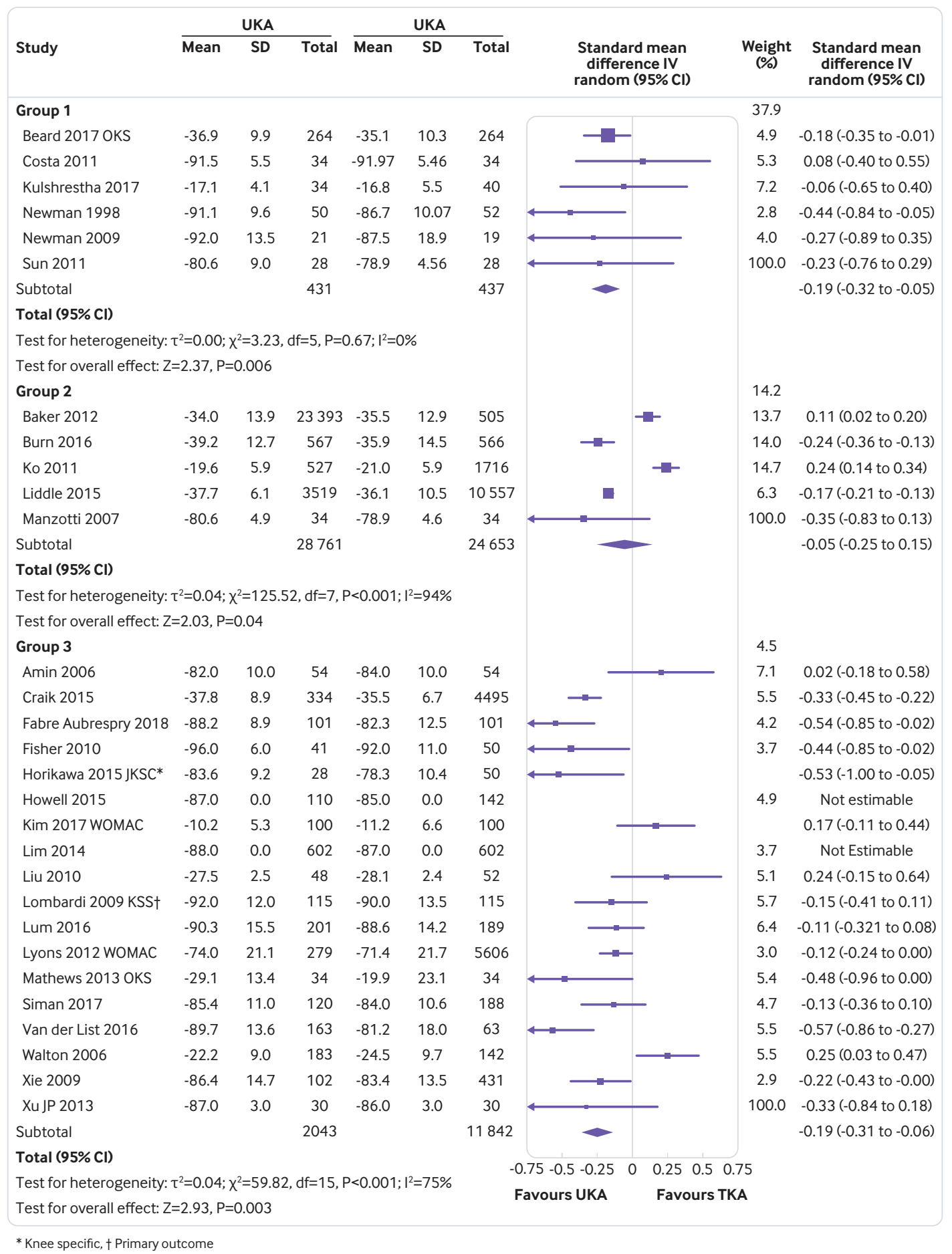

Fig 5 | Forest plot comparing combined pain and function measured using knee specific patient reported outcome measures after unicompartmental (UKA) versus total knee replacement (TKA). Also appears in the supplementary material as supplementary figure 10 . IV=inverse variance weighting; $0 K S=0 x f o r d$ knee score; JKSC=Japanese knee osteoarthritis score; WOMAC=Western Ontario McMaster Universities osteoarthritis index; KSS=Knee Society Score; JOA=Japanese orthopaedic association score

four cohort studies 96108110121 in the group 3 analysis showed an overall standard mean difference of -0.08 $(-0.35$ to -0.20$)$.

Function scores-Sixteen studies, including a maximum of 3011 UKA and 10470 TKA procedures, reported either function specific PROM scores or the function element of a larger combined PROM score. A higher score related to a better clinical outcome. In this analysis, significantly higher functional PROM scores were achieved after UKA than after TKA in groups 2 
confidence interval 0.19 to 2.14). Data from eight studies included in group $2^{73757678-80} 97123124$ showed a risk ratio of 1.85 (1.43 to 2.38). Group 3 included data from four cohort studies, ${ }^{85} 919497$ which showed a risk ratio of 1.68 (1.07 to 2.64 ).

\section{Revision at 15 years}

Three studies presented data regarding revision rates or survival of UKA and TKA to 15 years, on a maximum of 6651 UKA and 132168 TKA procedures. Revision rates were higher after UKA than TKA in group 2, but reported as lower in the one group 1 trial, although this group 1 result was not significant (supplementary figure 17). In group 1, the one randomised controlled trial $^{69}$ reported revision rates at 15 years, showing a marginally lower revision rate after UKA than after TKA at this time point, with an overall risk ratio of 0.64 (95\% confidence interval 0.19 to 2.14 ). Two group 2 studies ${ }^{7176}$ showed an overall risk ratio of 5.18 (1.39 to 19.22). No data were available from studies in group 3.

\section{Domain 5: rate of recovery}

Return to work or sport

Limited comparative studies were available for inclusion under our search criteria for speed of recovery, with several different methods of reporting speed of recovery. No data were available from studies in groups 1 or 2 . Group 3 included two cohort studies $^{3795}$ reporting the time rate (in weeks) of return to work after UKA or TKA, including data from 146 UKA and 156 TKA procedures. We saw a quicker return to work after UKA than after TKA (supplementary figure 18). The analysis from the two group 3 studies showed an overall mean difference of -0.96 (95\% confidence interval -1.31 to -0.61). No data were presented from group 1 or 2 studies regarding the return to sport after UKA or TKA. In group 3, two cohort studies ${ }^{95}{ }^{110}$ could be included in the analysis, with results from 151 UKA and 155 TKA procedures. In the data presented, return to sport was marginally quicker after UKA than after TKA. The analysis from the two cohort studies showed an overall mean difference of -5.24 weeks $(-6.84$ to -3.64; supplementary figure 19).

\section{Discussion}

The present study, comparing unicompartmental and total knee arthroplasty, provides a synthesis of evidence from randomised controlled trials, national and nationwide registries, and cohort studies, including all outcome domains identified as important

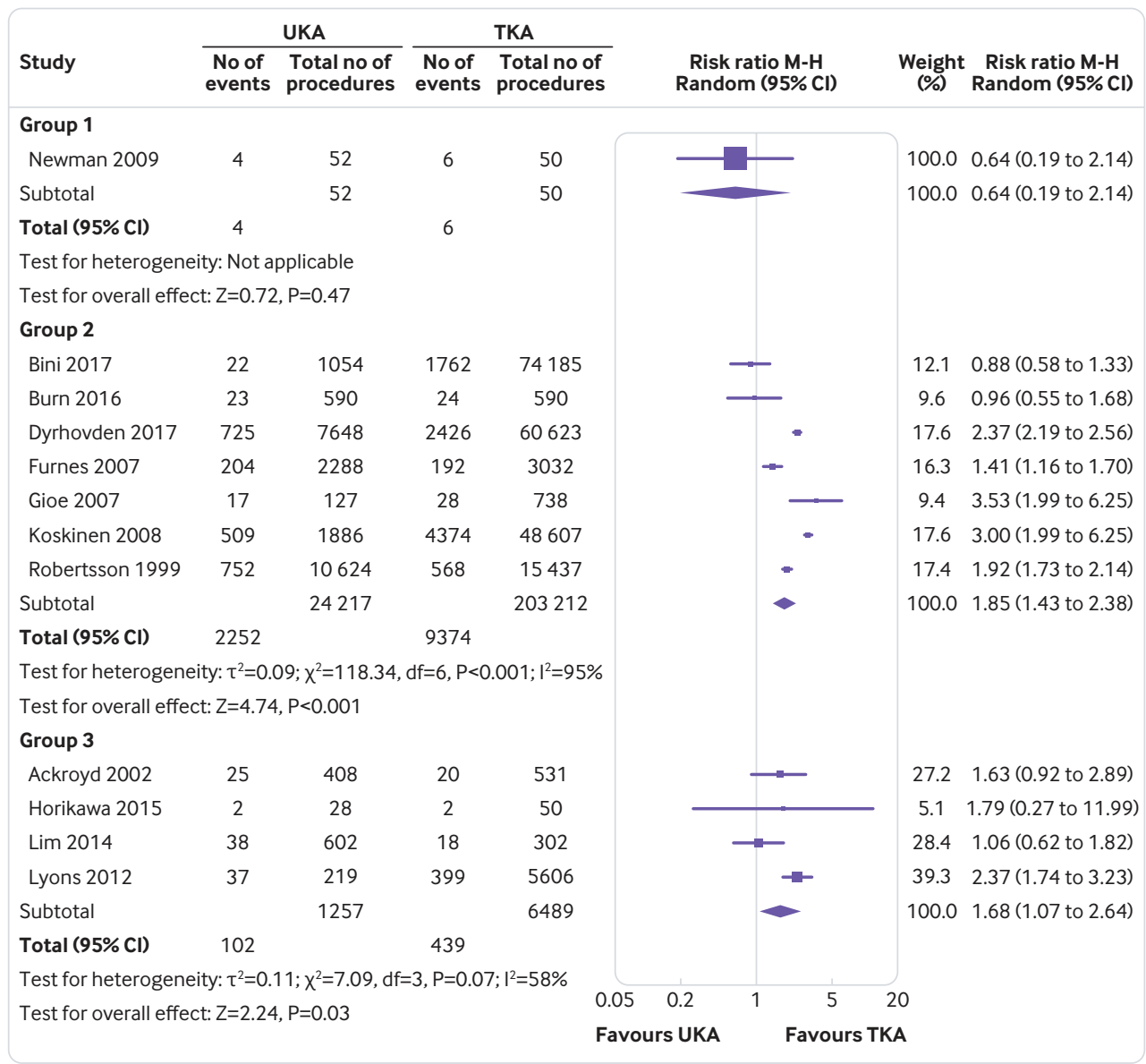

Fig 7 | Forest plot comparing incidence of revision at 10 years after unicompartmental (UKA) versus total knee replacement (TKA). Also appears in the supplementary material as supplementary figure $16 . \mathrm{M}-\mathrm{H}=\mathrm{Mantel}$-Haenszel test 
by patients. The study aimed to provide evidence to support informed shared decision making in the care of patients presenting with medial unicompartmental osteoarthritis of the knee.

\section{Main findings}

A large amount of research was used to address the aim of this study. With the selected search criteria, 60 studies presented data comparing UKA with TKA, and were included for analysis in the present study. Analysis of this data showed significant differences in outcomes between UKA and TKA, with advantages associated with UKA across multiple outcome domains. In domain 1 , patients undergoing a UKA had significantly shorter operating times than those undergoing TKA in data from groups 2 and 3. Furthermore, patients undergoing UKA were shown to have significantly shorter hospital stays in all study groups analysed.

In domain 2, fewer early complications were seen in those patients undergoing UKA than in those undergoing TKA. Incidence of myocardial infarctions was only reported in a small number of studies. The only randomised controlled trial in group 1 and the registry and database data in group 2 studies showed a significantly higher risk of myocardial infarction after TKA than UKA, and group 3 studies showed equivocal results. Cerebrovascular events were reported in only two studies from group 2, which showed an increased risk of a patient having an event after TKA than after UKA (relative risk ratio 0.34 (95\% confidence interval 0.15 to 0.74$)$ ). Fewer events of venous thromboembolism were reported after UKA than TKA, but the relative risk was only significantly different in the registry data (risk ratio 0.39 (0.27 to 0.57$)$ ). The risk of developing a deep infection was higher after TKA than after UKA at all levels where analysis was possible. The single randomised controlled trial reporting data on this outcome was not large enough to show any infections. However, analysis of study groups 2 and 3 showed a significant difference (relative risk ratio 0.59 (0.43 to 0.82$)$ and 0.40 (0.16 to 1.01), respectively). It was not possible to calculate the risk ratio of mortality after UKA or TKA with studies in groups 1 or 3 , because they were too small to capture this outcome. However, the larger database and registry studies in group 2 showed a significant increased risk of mortality after TKA than after UKA (risk ratio 0.27 (0.16 to 0.46$), Z=5.02, P \leq 0.001$ ).

In domain 3, group 1 studies did not show a significant difference in the range of movement. However, a significant improvement was seen in those patients receiving a UKA than in those receiving TKA in group 2 and 3 studies. In the limited analysis possible for postoperative kneeling ability, patients undergoing UKA had significantly better results (risk ratio 0.53 (95\% confidence interval 0.28 to 1.01). PROM scores were reported to be significantly better after UKA than TKA in groups 1 and 3, but not significantly better in group 2 studies. For isolated pain scores, no significant difference was seen between UKA and TKA. However, UKA had better scores in functional PROMs scores, with significant results in the group 2 and 3 analyses.
In domain 4, reoperation rates were equivalent between UKA and TKA, with the only significant result in the group 3 analysis showing fewer reoperations after UKA when MUAs manipulations under anaesthetic were included. Revision rates were significantly better in all study groups for TKA versus UKA at five years. Only one randomised controlled trial in group 1 reported data up to 10 and 15 years, showing a non-significant reduction in revision rate after UKA. However, group 2 studies reporting data at 10 and 15 years showed consistently significantly better revision rates for TKA than for UKA.

For domain 5, only limited data were available for the rate of recovery. However, for return to work and return to sporting activities, a significantly quicker recovery was seen after UKA than after TKA (mean difference -0.96 (95\% confidence interval -1.31 to $-0.61), \mathrm{P}<0.001,-5.24$ (-6.84 to -3.64$), \mathrm{P}<0.001$, respectively).

\section{Comparison with other studies}

We are not aware of any other study that has used our approach, but useful comparison can be made with previous systematic reviews, meta-analyses, and simple cohort studies. Arirachakaran and colleagues published a systematic review ${ }^{125}$ that included only randomised controlled trial data. This review reported similar results with significantly better function PROMs scores, range of movement after UKA, equivocal pain PROMs scores, and lower revision rates after TKA. Longo and colleagues, ${ }^{126}$ in reviewing the data available for UKA and TKA in the same patient, concluded that the only significant difference was an improved range of movement after UKA. More recently, Mohammad and colleagues ${ }^{28}$ did a meta-analysis on outcomes after the "Oxford" (Biomet) medial unicompartmental knee arthroplasty, showing a similar set of outcome advantages for this specific UKA device. Furthermore, Burn and colleagues $^{27}$ investigated the economic implications of choosing between UKA and TKA. They found that despite a higher revision rate, patients receiving UKA had shorter hospital stays, quicker recovery periods, and reduced complication rates, and with an earlier return to work these patients have a reduced economic impact compared with those receiving TKA. This review shows very similar findings to our present study and to another analysis ${ }^{127}$ showing a quicker return to activities in younger patients.

The lower revision results for UKA than for TKA shown in our study are supported by other published literature. ${ }^{6}$ Annual reports from national registries have shown consistently higher revision rates for UKA than for TKA. ${ }^{5128}$ Further analysis of national joint registry data has allowed greater insight into the higher revision rate seen with UKA practice. The Nordic registries have reported a significantly higher implant survival of UKA at 10 years in centres that perform more than 11 UKA procedures per year, ${ }^{129}$ with the lowest revision rate seen in those centres performing more than 40 procedures a year. ${ }^{130}$ Robertsson and 
colleagues had reported a similar trend in the Swedish Knee Arthroplasty Register. ${ }^{131}$ Baker and colleagues ${ }^{132}$ showed increased revision rates in the UK National Joint Registry (NJR) for those surgeons performing fewer than 13 UKA procedures per year, and a greater propensity to revise UKA for unexplained pain.

Additionally, Liddle and colleagues ${ }^{8}$ showed that surgeons who report at least $20 \%$ of their arthroplasty practice as UKA achieve lower rates of revision, but that over $80 \%$ of surgeons performing UKA in the UK who enter data to the National Joint Registry performed fewer than 10 UKA procedures per year. Furthermore, single centre cohort studies, which used methods outside the scope of the present study, have shown that similar revision rates can be achieved for TKA and UKA. ${ }^{911} 12121$ Hamilton and colleagues ${ }^{133}$ showed a reduced revision rate in those studies undertaken in high volume centres, although the strength of this evidence was weak. These results are considered to be related to the expertise and experience of the operating surgeons, producing better results, and their units having a higher threshold for revision surgery for unexplained pain and better postoperative support. Furthermore, more equivocal revision rates after UKA versus TKA (than those shown in the present study) have been reported in studies solely reporting outcomes on individual implants. ${ }^{134}$

Our methodology included insufficient studies to accurately analyse patients' return to work or sporting activities after UKA and TKA. Published studies comparing all types of lower limb interventions, or UKA and TKA individually, were analysed by Witjes and colleagues, ${ }^{135}$ who found $36-89 \%$ and $75-100 \%$ of patients returned to sport after TKA and UKA, respectively, with a return to low impact sports at 12 weeks after UKA and 13 weeks after TKA.

\section{Strengths and limitations}

We have demonstrated the lack of good quality data from randomised controlled trials comparing outcomes of TKA with UKA, particularly pertaining to outcome measures important to patients such as returning to work and kneeling ability after the procedure. Ongoing studies such as TOPKAT ${ }^{119}$ will provide more high level evidence but have not been designed to investigate all of these outcome measures.

This study includes analysis of all levels of evidence, from level 1 trial data to level 4 cohort data, which has allowed a wide inclusion of studies and therefore a large number of individual cases. The inclusion of multiple study types does introduce significant heterogeneity (supplementary table 3), which would therefore affect the robustness of this study's conclusions. However, the use of trial data, reports from national joint registries and national multicentre databases, and large cohort studies has allowed inclusion of as much data as possible, such as good quality research data from smaller studies, which can often be missed in systematic reviews. Despite our extensive search strategy, relevant studies for inclusion could have been missed, but on repeat searches using modified language, no new historical studies were identified. We decided to include studies from only the past 20 years to discount data from very early implant designs, and to remove some of the effect of the development of new implant designs and implanting techniques.

Our literary search confirmed the paucity of trial data in this field comparing TKA with UKA. The lack of level 1 data from randomised controlled trials does reduce the robustness of our conclusions, because there were only five trials comparing UKA with TKA, of which only four reported data on outcomes greater than one year, involving only 156 patients in total. Furthermore, despite the large number of studies reported, they varied in inclusion criteria, population demographics, end assessment points and methods, and varying degrees of statistical adjustment. The five year results from the TOPKAT study, the largest trial in this field, will offer an important contribution to the evidence base, and more high quality studies will be required. ${ }^{66}$

Inclusion of data from joint registry studies and large, multicentre, nationwide database studies might be considered controversial in such an analysis, because the data they present have many variables that are often not accounted for, such as detailed breakdown of multiple implant types, the grade of surgeon, surgical approaches, and centre experience. However, the value and feasibility of using these data has been highlighted, ${ }^{136}$ and meta-analysis of their outcomes has also been presented..$^{137-139}$ One value of these studies is their size and statistical power, enabling differences in rare complications such as mortality rate. ${ }^{13}$ In addition, because implant survival and revision rates are likely to be affected by the experience of the operating surgeon and centre performing the procedure, registry data could be considered valuable "real world" data.

Another limitation of the study is that data from registry and large national multicentre database studies (group 2) tended to dominate the outcome domains they were included in, given the large patient numbers included in these studies. The effect of this limitation is uncertain, because these data have been recognised to include flaws owing to incomplete or inaccurate data collection. ${ }^{140-143}$ Furthermore, data from studies in groups 2 and 3 were largely based on unmatched patient cohorts in relation to their preoperative disease severity or pattern, which could have resulted in a protopathic bias.

This study did not present data on all the outcome domains identified by the literature search. Aspects of UKA or TKA design were not explored in the current study, because further subdivision of the data could have diminished the validity of any conclusions drawn. Surgical approach was considered, but the studies identified were not comparative between UKA and TKA, and patients were often more concerned about the length of the scar, which is rarely reported. Blood loss or need for transfusion was discussed as a potential outcome domain but was thought to be a less important factor within the patient decision 
group. Lastly, cost effectiveness of UKA versus TKA featured highly in the literature search, and has been extensively studied in previous analyses. ${ }^{31-33}$ Despite this factor being significant for healthcare providers, the present study was designed to aid patient decision making, and demonstrating cost implications could have unfairly influenced patients.

Despite its limitations, the study design followed appropriate methodology, and included many studies that reported data across multiple outcome domains on a substantial number of patients and implants. With this analysis, we aimed to provide the most complete representation possible of the differences in outcome between UKA and TKA.

\section{Interpretation of available data}

This study aimed to have immediate and practical relevance in helping to inform a patient centred, shared decision making process when deciding between UKA and TKA treatment for unicompartmental osteoarthritis. The need to choose between treatments could apply to $25-47 \%$ of patients presenting with primary osteoarthritis. ${ }^{2}$ This study showed some benefits for UKA over TKA in some outcome domains, including reduced length of stay in hospital, better functional outcome, and fewer medical complications. But in the longer term, the risk of revision was higher with UKA than TKA, although overall reoperation rate is lower. Our study highlights that a multidimensional approach to determining outcome is required when different treatment options are available for a single condition and there is no consensus on the best option. $^{144}$

The most important beneficiaries of the outcome of our analyses are patients, who must decide which treatment option they wish to pursue. Their final decision will hinge on the relative value they place on the advantages and disadvantages of each treatment option. At present, many UK knee surgeons do not perform UKA, preferring to use TKA as their sole treatment option. As the case for UKA as a viable treatment option increases, more surgeons could offer UKA or refer to appropriate specialists. If such changes in patient and clinician preference occur, then the proportion of UK primary knee arthroplasties performed as UKA could increase from the present level of $8 \% .^{5}$

Contributors: HAW was responsible for the design of study, data collection, analysis, and writing of the paper. RM and SGFA were responsible for the abstract review, data extraction, and text editing. SS and AA facilitated patient discussion groups to establish outcomes of domain to be studied. WFJ and NB provided patients for discussion groups, and contributed to the review and text editing. $\mathrm{SH}$ gave statistical support for data analysis. AJP is the senior author and contributed to the development of study design and text editing. SH and AJP are the study guarantors. The corresponding author attests that all listed authors meet authorship criteria and that no others meeting the criteria have been omitted.

Funding: No separate funding was supplied for this study.

Competing interests: All authors have completed the ICMJE uniform disclosure form at www.icmje.org/coi_disclosure.pdf and declare: no direct support from for the submitted work, however, there was institutional funding from Arthritis Research UK and National Institute for Health Research Oxford Biomedical Research Centre; the researchers and funders were independent; AJP has received research grants from Zimmer-Biomet, and personal consultancy fees from Zimmer Biomet and Depuy; WFJ has received personal consultancy fees from Zimmer-Biomet; NB has received support from ZimmerBiomet for educational consultancy and lectures.

Ethical approval: Ethical approval was not required for this analysis as all included data were already anonymised.

Data sharing: The full dataset and all technical appendices are available from the corresponding author. Consent was not obtained but the data presented are all anonymised and risk of identification is low.

The lead author affirms that the manuscript is an honest, accurate, and transparent account of the study being reported; that no important aspects of the study have been omitted; and that any discrepancies from the study as planned (and, if relevant, registered) have been explained.

This is an Open Access article distributed in accordance with the Creative Commons Attribution Non Commercial (CC BY-NC 4.0) license, which permits others to distribute, remix, adapt, build upon this work non-commercially, and license their derivative works on different terms, provided the original work is properly cited and the use is noncommercial. See: http://creativecommons.org/licenses/by-nc/4.0/.

1 Carr AJ, Robertsson O, Graves S, et al. Knee replacement. Lancet 2012;379:1331-40. doi:10.1016/S0140-6736(11) 60752-6

2 Willis-Owen CA, Brust K, Alsop H, Miraldo M, Cobb JP. Unicondylar knee arthroplasty in the UK National Health Service: an analysis of candidacy, outcome and cost efficacy. Knee 2009;16:473-8. doi:10.1016/j.knee.2009.04.006

3 Stern SH, Becker MW, Insall JN. Unicondylar knee arthroplasty. An evaluation of selection criteria. Clin Orthop Relat Res 1993;(286):143-8

4 Hamilton TW, Pandit HG, Jenkins C, Mellon SJ, Dodd CAF, Murray DW. Evidence-based indications for mobile-bearing unicompartmental knee arthroplasty in a consecutive cohort of thousand knees. J Arthroplasty 2017;32:1779-85. doi:10.1016/j. arth.2016.12.036

5 UK National Joint Registry. 13th annual report accessed online 2016. www.njrcentre.org.uk/njrcentre/Portals/0/Documents/ England/Reports/13th\%20Annual\%20Report/07950\%20NJR\%20 Annual\%20Report\%202016\%200NLINE\%20REPORT.pdf

6 Chawla H, van der List JP, Christ AB, Sobrero MR, Zuiderbaan HA, Pearle AD. Annual revision rates of partial versus total knee arthroplasty: A comparative meta-analysis. Knee 2017;24:179-90. doi:10.1016/j.knee.2016.11.006

7 W-Dahl A, Robertsson O, Lidgren L, Miller L, Davidson D, Graves S. Unicompartmental knee arthroplasty in patients aged less than 65 Acta Orthop 2010;81:90-4. doi:10.3109/17453671003587150

8 Liddle AD, Pandit H, Judge A, Murray DW. Optimal usage of unicompartmental knee arthroplasty: a study of 41,986 cases from the National Joint Registry for England and Wales. Bone Joint / 2015;97-B:1506-11. doi:10.1302/0301 620X.97B11.35551

9 Pandit H, Hamilton TW, Jenkins C, Mellon SJ, Dodd CA, Murray DW. The clinical outcome of minimally invasive Phase 3 Oxford unicompartmental knee arthroplasty: a 15-year follow-up of 1000 UKAs. Bone Joint / 2015;97-B:1493-500. doi:10.1302/0301620X.97B11.35634

10 Forster-Horváth C, Artz N, Hassaballa MA, et al. Survivorship and clinical outcome of the minimally invasive Uniglide medial fixed bearing, all-polyethylene tibia, unicompartmental knee arthroplasty at a mean follow-up of 7.3years. Knee 2016;23:981-6. doi:10.1016/j.knee.2016.07.003

11 Lisowski LA, Meijer LI, van den Bekerom MP, Pilot P, Lisowski AE. Tento 15 -year results of the Oxford Phase III mobile unicompartmental knee arthroplasty: a prospective study from a non-designer group. Bone Joint J 2016;98-B(Suppl B):41-7. doi:10.1302/0301620X.98B10.BJJ-2016-0474.R1

12 Bottomley N, Jones LD, Rout R, et al. A survival analysis of 1084 knees of the Oxford unicompartmental knee arthroplasty: a comparison between consultant and trainee surgeons. Bone Joint J 2016;98-B(Supple B):22-7. doi:10.1302/0301-620X.98B10.BJJ2016-0483.R1

13 Hunt LP, Ben-Shlomo Y, Clark EM, et al, National Joint Registry for England and Wales. 45-day mortality after 467,779 knee replacements for osteoarthritis from the National Joint Registry for England and Wales: an observational study. Lancet 2014;384:1429 36. doi:10.1016/S0140-6736(14)60540-7

14 Liddle AD, Judge A, Pandit H, Murray DW. Adverse outcomes after total and unicompartmental knee replacement in 101,330 matched patients: a study of data from the National Joint Registry for England 
and Wales. Lancet 2014;384:1437-45. doi:10.1016/S0140 6736(14)60419-0

15 Siman H, Kamath AF, Carrillo N, Harmsen WS, Pagnano MW, Sierra RJ. Unicompartmental knee arthroplasty vs total knee arthroplasty for medial compartment arthritis in patients older than 75 years: comparable reoperation, revision, and complication rates. I Arthroplasty 2017;32:1792-7. doi:10.1016/j.arth.2017.01.020

16 Elwyn G, Frosch D, Thomson R, et al. Shared decision making: a model for clinical practice. J Gen Intern Med 2012;27:1361-7. doi:10.1007/s11606-012-2077-6

17 Pickrell WO, Elwyn G, Smith PE. Shared decision-making in epilepsy management. Epilepsy Behav 2015;47:78-82. doi:10.1016/j. yebeh.2015.01.033

18 Hack TF, Degner LF, Watson P, Sinha L. Do patients benefit from participating in medical decision making? Longitudinal follow-up of women with breast cancer. Psychooncology 2006;15:9-19. doi:10.1002/pon.907

19 Coulter A. Measuring what matters to patients. BMJ 2017;356:j816. doi:10.1136/bmj.j816

20 Ross J, Santhirapala R, MacEwen C, Coulter A. Helping patients choose wisely. BMJ 2018;361:k2585. doi:10.1136/bmj.k2585

21 Franklin PD, Lewallen D, Bozic K, Hallstrom B, Jiranek W, Ayers DC Implementation of patient-reported outcome measures in U.S. total joint replacement registries: rationale, status, and plans. J Bone Joint Surg Am 2014:96(Suppl 1):104-9. doi:10.2106/JBJS.N.00328

22 Hunt LP, Ben-Shlomo Y, Whitehouse MR, Porter ML, Blom AW. The main cause of death following primary total hip and knee replacement for osteoarthritis: a cohort study of 26,766 deaths following 332,734 hip replacements and 29,802 deaths following 384,291 knee replacements. J Bone Joint Surg Am 2017;99:565-75. doi:10.2106/JBJS.16.00586

23 Liddle AD, Judge A, Pandit H, Murray DW. Adverse outcomes after total and unicompartmental knee replacement in 101,330 matched patients: a study of data from the National Joint Registry for England and Wales. Lancet 2014;384:1437-45. doi:10.1016/S0140 6736(14)60419-0

24 Civinini R, Carulli C, Matassi F, Lepri AC, Sirleo L, Innocenti M. The survival of total knee arthroplasty: current data from registries on tribology: review article. HSS / 2017;13:28-31. doi:10.1007/ s11420-016-9513-9

25 James Lind Alliance. http://www.jla.nihr.ac.uk/priority-settingpartnerships/hip-and-knee-replacement-for-osteoarthritis/top-10priorities/ 2017

26 Arirachakaran A, Choowit P, Putananon C, Muangsiri S, Kongtharvonskul J. Is unicompartmental knee arthroplasty (UKA) superior to total knee arthroplasty (TKA)? A systematic review and meta-analysis of randomized controlled trial. Eur J Orthop Surg Traumatol 2015;25:799-806. doi:10.1007/s00590-015-1610-9

27 Burn E, Liddle AD, Hamilton TW, et al. Choosing between unicompartmental and total knee replacement: what can economic evaluations tell us? A systematic review. PharmacoEconomics - Open, 2017.

28 Mohammad HR, Strickland L, Hamilton TW, Murray DW. Long-term outcomes of over 8,000 medial Oxford Phase 3 Unicompartmental Knees-a systematic review. Acta Orthop 2018;89:101-7. doi:10.108 $0 / 17453674.2017 .1367577$

29 Stroup DF, Berlin JA, Morton SC, et al. Meta-analysis of observational studies in epidemiology: a proposal for reporting. Meta-analysis Of Observational Studies in Epidemiology (MOOSE) group. JAMA 2000;283:2008-12. doi:10.1001/ jama.283.15.2008

30 Hutton B, Wolfe D, Moher D, Shamseer L. Reporting guidance considerations from a statistical perspective: overview of tools to enhance the rigour of reporting of randomised trials and systematic reviews. Evid Based Ment Health 2017;20:46-52. doi:10.1136/eb2017-102666

31 Peersman G, Jak W, Vandenlangenbergh T, Jans C, Cartier P, Fennema P. Cost-effectiveness of unicondylar versus total knee arthroplasty: a Markov model analysis. Knee 2014;21(Suppl 1):S3742. doi:10.1016/S0968-0160(14)50008-7

32 Slover J, Espehaug B, Havelin LI, et al. Cost-effectiveness of unicompartmental and total knee arthroplasty in elderly lowdemand patients. A Markov decision analysis. J Bone Joint Surg Am 2006;88:2348-55. doi:10.2106/JBJS.E.01033

33 Burn E, Liddle AD, Hamilton TW, et al. Cost-effectiveness of unicompartmental compared with total knee replacement: a population-based study using data from the National Joint Registry for England and Wales. BMJ Open 2018;8:e020977. doi:10.1136/ bmjopen-2017-020977

34 Schwab PE, Lavand'homme P, Yombi JC, Thienpont E. Lower blood loss after unicompartmental than total knee arthroplasty. Knee Surg Sports Traumatol Arthrosc 2015;23:3494-500. doi:10.1007/ s00167-014-3188-x

35 Higgins JP, Altman DG, Gøtzsche PC, et al, Cochrane Bias Methods Group, Cochrane Statistical Methods Group. The Cochrane
Collaboration's tool for assessing risk of bias in randomised trials. BMJ 2011;343:d5928. doi:10.1136/bmi.d5928

36 Wells G, Shea B, O'Connell D, et al. The Newcastle-Ottawa Scale (NOS) for assessing the quality of nonrandomised studies in metaanalyses. http://www.ohri.ca/programs/clinical_epidemiology/ oxford.asp.

37 Foote JA, Smith HK, Jonas SC, Greenwood R, Weale AE. Return to work following knee arthroplasty. Knee 2010;17:19-22. doi:10.1016/j. knee.2009.06.001

38 Ma G, Yin Z, Huang F, et al. [Short-term effectiveness of unicompartmental knee arthroplasty for medial compartmental knee osteoarthritis]. Zhongguo Xiu Fu Chong Jian Wai Ke Za Zhi 2014:28:1208-11.

39 Winder RP, Severson EP, Trousdale RT, Pagnano MW, Wood-Wentz CM, Sierra RJ. No difference in 90-day complications between bilateral unicompartmental and total knee arthroplasty. Am J Orthop (Belle Mead NJ) 2014;43:E30-3

40 Ollivier M, Parratte S, Argenson JN. Results and outcomes of unicompartmental knee arthroplasty[vii-viii.]. Orthop Clin North Am 2013;44:287-300, vii-viii. doi:10.1016/i.ocl.2013.03.004

41 Jenkins C, Barker KL, Pandit H, Dodd CA, Murray DW. After partial knee replacement, patients can kneel, but they need to be taught to do so: a single-blind randomized controlled trial. Phys Ther 2008;88:101221. doi:10.2522/ptj.20070374

42 Strain D, Li CS, Phillips M, Monteagudo Piqueras O, Bhandari M. Cost effectiveness and economic impact of the KineSpring knee implant system in the treatment of knee osteoarthritis in Spain. J Long Term Eff Med Implants 2015;25:225-35. doi:10.1615/ LongTermEffMedImplants.2015012728

43 Li CS, Seeger T, Auhuber TC, Bhandari M. Cost-effectiveness and economic impact of the KineSpring knee implant system in the treatment for knee osteoarthritis. Knee Surg Sports Traumatol Arthrosc 2013;21:2629-37. doi:10.1007/s00167-013-2427-x

44 Chen JQ, Gao S], Li T, Lu B, Shao DC, Wang JC. [Comparison of efficacies for two surgical methods in the treatment of medial tibialfemoral osteoarthritis]. Zhonghua Yi Xue Za Zhi 2012;92:36-9.

45 Leskinen J, Eskelinen A, Huhtala H, Paavolainen P, Remes V. The incidence of knee arthroplasty for primary osteoarthritis grows rapidly among baby boomers: a population-based study in Finland. Arthritis Rheum 2012:64:423-8, doi:10.1002/art.33367

46 Panni AS, Vasso M, Cerciello S, Felici A. Unicompartmental knee replacement provides early clinical and functional improvement stabilizing over time. Knee Surg Sports Traumatol Arthrosc 2012;20:579-85. doi:10.1007/s00167-011-1613-y

47 Kasch R, Merk S, Kayser R, et al. [Sledge versus bicondylar surface treatment in the endoprosthetic therapy for unicompartmental knee arthrtitis--a comparative cost analysis]. Z Orthop Unfall 2011;149:646-52. doi:10.1055/s-0031-1280248

48 Feeley BT, Gallo RA, Sherman S, Williams RJ. Management of osteoarthritis of the knee in the active patient. J Am Acad Orthop Surg 2010;18:406-16. doi:10.5435/00124635-20100700000003

49 Dalury DF, Fisher DA, Adams MJ, Gonzales RA. Unicompartmental knee arthroplasty compares favorably to total knee arthroplasty in the same patient. Orthopedics 2009;32:orthosupersite.com/view. asp? rID $=38057$.

50 W-Dahl A, Robertsson O, Lidgren L. Surgery for knee osteoarthritis in younger patients. Acta Orthop 2010;81:161-4. doi:10.3109/17453670903413186

51 Soohoo NF, Sharifi H, Kominski G, Lieberman JR. Cost-effectiveness analysis of unicompartmental knee arthroplasty as an alternative to total knee arthroplasty for unicompartmental osteoarthritis. J Bone loint Surg Am 2006;88:1975-82.

52 Harrysson OL, Robertsson O, Nayfeh JF. Higher cumulative revision rate of knee arthroplasties in younger patients with osteoarthritis. Clin Orthop Relat Res 2004;(421):162-8. doi:10.1097/01. blo.0000127115.05754.ce

53 Meyer M, Machner A, Pap G, Neumann HW. [Is unicondylar knee prosthesis a current possibility in primary management of varus gonarthrosis?--A prospective matched-pair study]. Z Orthop Ihre Grenzgeb 2000;138:204-8. doi:10.1055/s-2000-11275

54 Howell RE, Lombardi AVJr, Crilly R, Opolot S, Berend KR. Unicompartmental knee arthroplasty: does a selection bias exist? Arthroplasty 2015;30:1740-2. doi:10.1016/j.arth.2015.05.010

55 Miller S, Agarwal A, Haddon WB, et al. Comparison of gait kinetics in total and unicondylar knee replacement surgery. Ann R Coll Surg Engl 2018;100:267-74. doi:10.1308/rcsann.2017.0226

56 Friesenbichler B, Item-Glatthorn JF, Wellauer V, von Knoch F, Casartelli NC, Maffiuletti NA. Short-term functional advantages after medial unicompartmental versus total knee arthroplasty. Knee 2018;25:638-43. doi:10.1016/j.knee.2018.04.009

57 Tyagi V, Farooq M. Unicompartmental knee arthroplasty: indications, outcomes, and complications. Conn Med 2017;81:87-90.

58 Baumann F, Bahadin Ö, Krutsch W, et al. Proprioception after bicruciate-retaining total knee arthroplasty is comparable to 
unicompartmental knee arthroplasty. Knee Surg Sports Traumatol Arthrosc 2017;25:1697-704. doi:10.1007/s00167-016-4121-2

59 Zuiderbaan HA, van der List JP, Khamaisy S, et al. Unicompartmental knee arthroplasty versus total knee arthroplasty: which type of artificial joint do patients forget? Knee Surg Sports Traumatol Arthrosc 2017;25:681-6. doi:10.1007/s00167-015-3868-1

60 Wautier D, Thienpont E. Changes in anteroposterior stability and proprioception after different types of knee arthroplasty. Knee Surg Sports Traumatol Arthrosc 2017;25:1792-800. doi:10.1007/ s00167-016-4038-9

61 Nam D, Berend ME, Nunley RM, et al. Residual symptoms and function after unicompartmental and total knee arthroplasty: comparable to normative controls? J Arthroplasty 2016;31:2161-6. doi:10.1016/j.arth.2016.02.064

62 Sweeney K, Grubisic M, Marra CA, Kendall R, Li LC, Lynd LD. Comparison of HRQL between unicompartmental knee arthroplasty and total knee arthroplasty for the treatment of osteoarthritis. J Arthroplasty 2013;28(Suppl):187-90. doi:10.1016/j. arth.2013.05.009

63 Newman JH, Ackroyd CE, Shah NA. Unicompartmental or total knee replacement? Five-year results of a prospective, randomised trial of 102 osteoarthritic knees with unicompartmental arthritis. J Bone Joint Surg Br 1998;80:862-5. doi:10.1302/0301-620X.80B5.8835

64 Costa CR, Johnson AJ, Mont MA, Bonutti PM. Unicompartmental and total knee arthroplasty in the same patient. J Knee Surg 2011;24:273-8. doi:10.1055/s-0031-1280970

65 Sun PF, Jia YH. Mobile bearing UKA compared to fixed bearing TKA: a randomized prospective study. Knee 2012;19:103-6. doi:10.1016/j. knee.2011.01.006

66 Beard D, Price A, Cook J, et al. Total or Partial Knee Arthroplasty Trial - TOPKAT: study protocol for a randomised controlled trial. Trials 2013;14:292. doi:10.1186/1745-6215-14-292

67 Kulshrestha V, Datta B, Kumar S, Mittal G. Outcome of unicondylar knee arthroplasty vs total knee arthroplasty for early medial compartment arthritis: a randomized study. J Arthroplasty 2017;32:1460-9. doi:10.1016/j.arth.2016.12.014

68 Weale AE, Murray DW, Newman JH, Ackroyd CE. The length of the patellar tendon after unicompartmental and total knee replacement. J Bone Joint Surg Br 1999;81:790-5. doi:10.1302/0301620X.81B5.9590

69 Newman J, Pydisetty RV, Ackroyd C. Unicompartmental or total knee replacement: the 15 -year results of a prospective randomised controlled trial. J Bone Joint Surg Br 2009;91-b:52-7. doi:10.1302/0301-620X.91B1.20899

70 Baker PN, Petheram T, Avery PJ, Gregg PJ, Deehan DJ. Revision for unexplained pain following unicompartmental and total knee replacement. J Bone Joint Surg Am 2012;94:e126. doi:10.2106/ JBJS.K.00791

71 Niinimäki T, Eskelinen A, Mäkelä K, Ohtonen P, Puhto AP, Remes V. Unicompartmental knee arthroplasty survivorship is lower than TKA survivorship: a 27-year Finnish registry study. Clin Orthop Relat Res 2014:472:1496-501. doi:10.1007/s11999-013-3347-2

72 Liddle AD, Pandit H, Judge A, Murray DW. Patient-reported outcomes after total and unicompartmental knee arthroplasty: a study of 14,076 matched patients from the National Joint Registry for England and Wales. Bone Joint / 2015;97-B:793-801. doi:10.1302/0301 620X.97B6.35155

73 Robertsson O, Borgquist L, Knutson K, Lewold S, Lidgren L. Use of unicompartmental instead of tricompartmental prostheses for unicompartmental arthrosis in the knee is a cost-effective alternative. 15,437 primary tricompartmental prostheses were compared with 10,624 primary medial or lateral unicompartmental prostheses. Acta Orthop Scand 1999;70:170-5. doi:10.3109/17453679909011257

74 Lygre SH, Espehaug B, Havelin LI, Furnes O, Vollset SE. Pain and function in patients after primary unicompartmental and total knee arthroplasty. J Bone Joint Surg Am 2010;92:2890-7. doi:10.2106/ JBJS.I.00917

75 Dyrhovden GS, Lygre SHL, Badawy M, Gøthesen $\varnothing$, Furnes 0 . Have the causes of revision for total and unicompartmental knee arthroplasties changed during the past two decades? Clin Orthop Relat Res 2017;475:1874-86. doi:10.1007/s11999-017-5316-7

76 Koskinen E, Paavolainen P, Eskelinen A, Pulkkinen P, Remes V. Unicondylar knee replacement for primary osteoarthritis: a prospective follow-up study of 1,819 patients from the Finnish Arthroplasty Register. Acta Orthop 2007;78:128-35. doi:10.1080/17453670610013538

77 Pearse AJ, Hooper GJ, Rothwell A, Frampton C. Survival and functional outcome after revision of a unicompartmental to a total knee replacement: the New Zealand National Joint Registry. J Bone Joint Surg Br 2010;92-b:508-12. doi:10.1302/0301-620X.92B4.22659

78 Gioe TJ, Novak C, Sinner P, Ma W, Mehle S. Knee arthroplasty in the young patient: survival in a community registry. Clin Orthop Relat Res 2007;464:83-7.
79 Furnes O, Espehaug B, Lie SA, Vollset SE, Engesaeter LB, Havelin LI. Failure mechanisms after unicompartmental and tricompartmental primary knee replacement with cement. J Bone Joint Surg Am 2007;89:519-25. doi:10.2106/JBJS.F.00210

80 Bini SA, Cafri G, Khatod M. Midterm-adjusted survival comparing the best performing unicompartmental and total knee arthroplasties in a registry. J Arthroplasty 2017;32:3352-5. doi:10.1016/j. arth.2017.05.050

81 Duchman KR, Gao Y, Pugely AJ, Martin CT, Callaghan JJ. Differences in short-term complications between unicompartmental and total knee arthroplasty: a propensity score matched analysis. J Bone Joint Surg Am 2014;96:1387-94. doi:10.2106/JBJS.M.01048

82 Bolognesi MP, Greiner MA, Attarian DE, et al. Unicompartmental knee arthroplasty and total knee arthroplasty among Medicare beneficiaries, 2000 to 2009. J Bone Joint Surg Am 2013;95:e174. doi:10.2106/JBJS.L.00652

83 Courtney PM, Froimson MI, Meneghini RM, Lee GC, Della Valle CJ. Should Medicare remove total knee arthroplasty from its inpatient only list? A total knee arthroplasty is not a partial knee arthroplasty. J Arthroplasty 2018;33(7s):S23-7. doi:10.1016/j. arth.2017.11.028

84 Drager J, Hart A, Khalil JA, Zukor DJ, Bergeron SG, Antoniou J. Shorter hospital stay and lower 30-day readmission after unicondylar knee arthroplasty compared to total knee arthroplasty. J Arthroplasty 2016;31:356-61. doi:10.1016/j.arth.2015.09.014

85 Ackroyd CE, Whitehouse SL, Newman JH, Joslin CC. A comparative study of the medial St Georg sled and kinematic total knee arthroplasties. Ten-year survivorship. J Bone Joint Surg Br 2002;84:667-72. doi:10.1302/0301-620X.84B5.12404

86 Amin AK, Patton JT, Cook RE, Gaston M, Brenkel IJ. Unicompartmental or total knee arthroplasty?: Results from a matched study. Clin Orthop Relat Res 2006;451:101-6. doi:10.1097/01. blo.0000224052.01873.20

87 Artz NJ, Hassaballa MA, Robinson JR, Newman JH, Porteous AJ, Murray JR. Patient reported kneeling ability in fixed and mobile bearing knee arthroplasty. J Arthroplasty 2015;30:2159-63. doi:10.1016/j.arth.2015.06.063

88 Burn E, Sanchez-Santos MT, Pandit HG, et al. Ten-year patient-reported outcomes following total and minimally invasive unicompartmental knee arthroplasty: a propensity score-matched cohort analysis. Knee Surg Sports Traumatol Arthrosc 2018;26:1455-64. doi:10.1007/s00167-016-4404-7

89 Craik JD, El Shafie SA, Singh VK, Twyman RS. Revision of unicompartmental knee arthroplasty versus primary total knee arthroplasty. J Arthroplasty 2015;30:592-4. doi:10.1016/j. arth.2014.10.038

90 Fisher DA, Dalury DF, Adams MJ, Shipps MR, Davis K. Unicompartmental and total knee arthroplasty in the over 70 population. Orthopedics 2010;33:668.

91 Horikawa A, Miyakoshi N, Shimada Y, Kodama H. Comparison of clinical outcomes between total knee arthroplasty and unicompartmental knee arthroplasty for osteoarthritis of the knee: a retrospective analysis of preoperative and postoperative results. I Orthop Surg Res 2015;10:168. doi:10.1186/s13018-015-0309-2

92 Ko Y, Narayanasamy S, Wee HL, et al. Health-related quality of life after total knee replacement or unicompartmental knee arthroplasty in an urban asian population. Value Health 2011;14:322-8 doi:10.1016/j.jval.2010.08.005

93 Liddle AD, Judge A, Pandit H, Murray DW. Determinants of revision and functional outcome following unicompartmental knee replacement. Osteoarthritis Cartilage 2014;22:1241-50. doi:10.1016/j.joca.2014.07.006

94 Lim JW, Cousins GR, Clift BA, Ridley D, Johnston LR. Oxford unicompartmental knee arthroplasty versus age and gender matched total knee arthroplasty - functional outcome and survivorship analysis. / Arthroplasty 2014:29:1779-83. doi:10.1016/j. arth.2014.03.043

95 Lombardi AVJr, Berend KR, Walter CA, Aziz-Jacobo J, Cheney NA. Is recovery faster for mobile-bearing unicompartmental than total knee arthroplasty? Clin Orthop Relat Res 2009;467:1450-7. doi:10.1007/ s11999-009-0731-z

96 Lum ZC, Lombardi AV, Hurst JM, Morris MJ, Adams JB, Berend KR. Early outcomes of twin-peg mobile-bearing unicompartmental knee arthroplasty compared with primary total knee arthroplasty. Bone Joint J 2016;98-B(Supple B):28-33. doi:10.1302/0301 620X.98B10.BJJ-2016-0414.R1

97 Lyons MC, MacDonald SJ, Somerville LE, Naudie DD, McCalden RW. Unicompartmental versus total knee arthroplasty database analysis: is there a winner? Clin Orthop Relat Res 2012;470:84-90. doi:10.1007/s11999-011-2144-z

98 Manzotti A, Confalonieri N, Pullen C. Unicompartmental versus computer-assisted total knee replacement for medial compartment knee arthritis: a matched paired study. Int Orthop 2007:31:315-9. doi:10.1007/s00264-006-0184-x 
99 Matthews DJ, Hossain FS, Patel S, Haddad FS. A cohort study predicts better functional outcomes and equivalent patient satisfaction following UKR compared with TKR. HSS / 2013;9:21-4. doi:10.1007/ s11420-012-9326-4

100 van der List JP, Chawla H, Zuiderbaan HA, Pearle AD. The role of preoperative patient characteristics on outcomes of unicompartmental knee arthroplasty: a meta-analysis critique. J Arthroplasty 2016;31:2617-27. doi:10.1016/j.arth.2016.04.001

101 Weale AE, Halabi OA, Jones PW, White SH. Perceptions of outcomes after unicompartmental and total knee replacements. Clin Orthop Relat Res 2001;(382):143-53. doi:10.1097/00003086200101000-00021

102 Williams DP, Price AJ, Beard DJ, et al. The effects of age on patientreported outcome measures in total knee replacements. Bone Joint / 2013;95-B:38-44. doi:10.1302/0301-620X.95B1.28061

103 Xu JP Xu WD, Lin GB, et al. [The clinical comparison of double knee osteoarthritis patients undergoing unicompartmental knee arthroplasty and total knee arthroplasty]. Zhonghua Wai Ke Za Zhi 2013;51:157-60.

104 Yang S, Hadlow S. Unicompartmental knee arthroplasty: is it durable? N Z Med J 2003;116:U627

105 Xie F, Lo NN, Tarride JE, O’Reilly D, Goeree R, Lee HP. Total or partial knee replacement? Cost-utility analysis in patients with knee osteoarthritis based on a 2-year observational study. Eur J Health Econ 2010;11:27-34. doi:10.1007/s10198-009-0154-5

106 Liu ZH, Guo WS, Zhang QD, Cheng LM. [Comparison of shortmedian term outcome between total knee arthroplasty and unicondylar arthroplasty in patients with osteoarthritis affected with medial compartment mainly of the knee]. Zhonghua Yi Xue Za Zhi 2010;90:2597-600.

107 Berger RA, Kusuma SK, Sanders SA, Thill ES, Sporer SM. The feasibility and perioperative complications of outpatient knee arthroplasty. Clin Orthop Relat Res 2009:467:1443-9. doi:10.1007/s11999-0090736-7

108 Kim MS, Koh IJ, Choi YJ, Lee JY, In Y. Differences in patient-reported outcomes between unicompartmental and total knee arthroplasties: a propensity score-matched analysis. J Arthroplasty 2017;32:14539. doi:10.1016/j.arth.2016.11.034

109 Jones GG, Kotti M, Wiik AV, et al. Gait comparison of unicompartmental and total knee arthroplasties with healthy controls. Bone Joint / 2016;98-B(Supple B):16-21. doi:10.1302/0301-620X.98B10.BJJ.2016.0473.R1

110 Ho JC, Stitzlein RN, Green CJ, Stoner T, Froimson MI. Return to sports activity following UKA and TKA. J Knee Surg 2016;29:254-9.

111 Lum ZC, Crawford DA, Lombardi AV Jr, et al. Early comparative outcomes of unicompartmental and total knee arthroplasty in severely obese patients. Knee 2018;25:161-6. doi:10.1016/j. knee.2017.10.006

112 Fabre-Aubrespy M, Ollivier M, Pesenti S, Parratte S, Argenson JN. Unicompartmental knee arthroplasty in patients older than 75 results in better clinical outcomes and similar survivorship compared to total knee arthroplasty. A matched controlled study. J Arthroplasty 2016:31:2668-71. doi:10.1016/j.arth.2016.06.034

113 Goh GS, Bin Abd Razak HR, Tay DK, Chia SL, Lo NN, Yeo S). Unicompartmental knee arthroplasty achieves greater flexion with no difference in functional outcome, quality of life, and satisfaction vs total knee arthroplasty in patients younge than 55 years. A propensity score-matched cohort analysis. J Arthroplasty 2018;33:355-61. doi:10.1016/j.arth.2017.09.022

114 van der List JP, Kleeblad LI, Zuiderbaan HA, Pearle AD. Mid-term outcomes of metal-backed unicompartmental knee arthroplasty show superiority to all-polyethylene unicompartmental and total knee arthroplasty. HSS / 2017;13:232-40. doi:10.1007/s11420017-9557-5

115 Shankar S, Tetreault MW, Jegier BJ, Andersson GB, Della Valle CJ. A cost comparison of unicompartmental and total knee arthroplasty. Knee 2016;23:1016-9. doi:10.1016/j.knee.2015.11.012

116 Schwab PE, Lavand'homme P, Yombi JC, Thienpont E. Lower blood loss after unicompartmental than total knee arthroplasty. Knee Surg Sports Traumatol Arthrosc 2015;23:3494-500. doi:10.1007| s00167-014-3188-x

117 Berger RA, Nedeff DD, Barden RM, et al. Unicompartmental knee arthroplasty. Clinical experience at 6- to 10-year followup. Clin Orthop Relat Res 1999;(367):50-60

118 Yang Z, Liu H, Xie X, Tan Z, Qin T, Kang P. The influence of diabetes mellitus on the post-operative outcome of elective primary total knee replacement: a systematic review and meta-analysis. Bone Joint / 2014;96-B:1637-43. doi:10.1302/0301-620X.96B12.34378

119 Beard DJ, Price AJ, Cook J, et al. Total or partial knee replacement for medial osteoarthritis? Early results from the TOPKAT trial. Arthroscopy 2017;33:e91-210.1016/j.arthro.2017.08.091

120 Walton NP, Jahromi I, Lewis PL, Dobson PJ, Angel KR, Campbell DG. Patient-perceived outcomes and return to sport and work: TKA versus mini-incision unicompartmental knee arthroplasty. I Knee Surg 2006;19:112-6. doi:10.1055/s-0030-1248089
121 Kim KT, Lee S, Kim JH, Hong SW, Jung WS, Shin WS. The survivorship and clinical results of minimally invasive unicompartmental knee arthroplasty at 10-year follow-up. Clin Orthop Surg 2015:7:199-206. doi:10.4055/cios.2015.7.2.199

122 Liddle AD, Judge A, Pandit H, Murray DW. Determinants of revision and functional outcome following unicompartmental knee replacement. Osteoarthritis Cartilage 2014;22:1241-50. doi:10.1016/j.joca.2014.07.006

123 Pandit H, Spiegelberg B, Clavé A, McGrath C, Liddle AD, Murray DW. Aetiology of lateral progression of arthritis following Oxford medial unicompartmental knee replacement: a case-control study. Musculoskelet Surg 2016;100:97-102. doi:10.1007/s12306-0150394-8

124 Burn E, Sanchez-Santos MT, Pandit HG, et al. Ten-year patient-reported outcomes following total and minimally invasive unicompartmental knee arthroplasty: a propensity score-matched cohort analysis. Knee Surg Sports Traumatol Arthrosc 2018;26:1455-64. doi:10.1007/s00167-016-4404-7

125 Arirachakaran A, Choowit P, Putananon C, Muangsiri S, Kongtharvonskul J. Is unicompartmental knee arthroplasty (UKA) superior to total knee arthroplasty (TKA)? A systematic review and meta-analysis of randomized controlled trial. Eur J Orthop Surg Traumatol 2015;25:799-806. doi:10.1007/s00590-015-1610-9

126 Longo UG, Loppini M, Trovato U, Rizzello G, Maffulli N, Denaro V. No difference between unicompartmental versus total knee arthroplasty for the management of medial osteoarthtritis of the knee in the same patient: a systematic review and pooling data analysis. Br Med Bull 2015;114:65-73. doi:10.1093/bmb/ldv009

127 Kleeblad LJ, van der List JP, Zuiderbaan HA, Pearle AD. Larger range of motion and increased return to activity, but higher revision rates following unicompartmental versus total knee arthroplasty in patients under 65: a systematic review. Knee Surg Sports Traumatol Arthrosc 2018;26:1811-22. doi:10.1007/s00167-017-4817-y

128 Aram P, Trela-Larsen L, Sayers A, et al. Estimating an individual's probability of revision surgery after knee replacement: a comparison of modeling approaches using a national data set. Am J Epidemiol 2018;187:2252-62. doi:10.1093/aje/kwy121

129 Badawy M, Fenstad AM, Bartz-Johannessen CA, et al. Hospital volume and the risk of revision in Oxford unicompartmental knee arthroplasty in the Nordic countries -an observational study of 14,496 cases. BMC Musculoskelet Disord 2017;18:388. doi:10.1186/s12891017-1750-7

130 Badawy M, Espehaug B, Indrekvam K, Havelin LI, Furnes O. Higher revision risk for unicompartmental knee arthroplasty in low-volume hospitals. Acta Orthop 2014;85:342-7. doi:10.3109/17453674.20 14.920990

131 Robertsson O, Knutson K, Lewold S, Lidgren L. The routine of surgical management reduces failure after unicompartmental knee arthroplasty. J Bone Joint Surg Br 2001;83:45-9. doi:10.1302/0301$620 \times 83 B 1.10871$

132 Baker P, Jameson S, Critchley R, Reed M, Gregg P, Deehan D. Center and surgeon volume influence the revision rate following unicondylar knee replacement: an analysis of 23,400 medial cemented unicondylar knee replacements. J Bone Joint Surg Am 2013;95:702 9. doi:10.2106/JBJS.L.00520

133 Hamilton TW, Rizkalla JM, Kontochristos L, et al. The interaction of caseload and usage in determining outcomes of unicompartmental knee arthroplasty: a meta-analysis. J Arthroplasty 2017;32:32283237.e2. doi:10.1016/j.arth.2017.04.063

134 van der List JP, Sheng DL, Kleeblad LJ, Chawla H, Pearle AD. Outcomes of cementless unicompartmental and total knee arthroplasty: A systematic review. Knee 2017;24:497-507. doi:10.1016/j.knee.2016.10.010

135 Witjes S, Gouttebarge V, Kuijer PPFM, van Geenen RCI, Poolman RW, Kerkhoffs GMMJ. Return to sports and physical activity after total and unicondylar knee arthroplasty: a systematic review and meta-analysis. Sports Med 2016;46:269-92. doi:10.1007/s40279-015-0421-9

136 Paxton EW, Mohaddes M, Laaksonen I, et al. Meta-analysis of individual registry results enhances international registry collaboration. Acta Orthop 2018;89:369-73. doi:10.1080/174536 74.2018.1454383

137 Labek G, Thaler M, Janda W, Agreiter M, Stöckl B. Revision rates after total joint replacement: cumulative results from worldwide joint register datasets. J Bone Joint Surg Br 2011;93-b:293-7. doi:10.1302/0301-620X.93B3.25467

138 Namba R, Graves S, Robertsson O, et al. International comparative evaluation of knee replacement with fixed or mobile non-posteriorstabilized implants. J Bone Joint Surg Am 2014;96(Suppl 1):52-8. doi:10.2106/JBJS.N.00466

139 Allepuz A, Havelin L, Barber T, et al. Effect of femoral head size on metal-on-HXLPE hip arthroplasty outcome in a combined analysis of six national and regional registries. J Bone Joint Surg Am 2014;96(Suppl 1):12-8. doi:10.2106/JBJS.N.00461

140 Kosy JD, Kassam A-AM, Hockings M. National Joint Registry data inaccuracy: a threat to proper reporting. Br J Hosp Med (Lond) 2013;74:691-3. doi:10.12968/hmed.2013.74.12.691 
141 Cobb J. Arthroplasty registries, patient safety and outlier surgeons: the case for change. Acta Orthop Belg 2015;81:594-9.

142 Palmer AJR, Dimbylow D, Giritharan S, Deo S. How accurate is National Joint Registry data? J Bone Joint Surg 2012;94-B(Suppl XXIX):73.

143 Jayatilaka MLT, Perry D, Cope MR. Accuracy of the National Joint

Registry data at a surgeon level: a comparison of three years of data entry between the national joint registry and an individual surgeons e logbook.Orthopaedic Proceedings 2013;95-B(Suppl 27):14
144 Beard DJ, Holt MD, Mullins MM, Malek S, Massa E, Price AJ. Decision making for knee replacement: variation in treatment choice for late stage medial compartment osteoarthritis. Knee 2012;19:886-9. doi:10.1016/j.knee.2012.05.005

Web appendix 1: Supplementary tables Web appendix 2: Supplementary figures 